\title{
Straw Incorporation Strategy on Cereal Crop Yield in China
}

\author{
Hong Zhao, Binfeng Sun, Fei Lu,^ Guo Zhang, Xiaoke Wang, and Zhiyun Ouyang
}

\begin{abstract}
Straw incorporation (SI) is considered a valid agricultural measure for ameliorating soil quality and sequestrating soil $\mathrm{C}$. This study aimed to quantitatively summarize the response of cereal yield to SI management. Our results showed that compared with straw removal, SI could significantly enhance cereal yield by $7 \%$ over all of China across the 9-yr period. In all regions, SI in coarse-textured soils increased yields more than in fine-textured soils. Straw incorporation resulted in greater yield increases for upland crops compared with rice (Oryza sativa L.) cropping, and for rotary tillage compared with plowing and no tillage. Overall, SI-induced cereal yield increases were greater in areas with a lack of soil nutrients and soil water. The SI-induced increases of $1 \mathrm{tha}^{-1}$ of soil organic $\mathrm{C}$ (SOC) storage could increase cereal yield by $44 \mathrm{~kg} \mathrm{ha}^{-1}$. If half or full amounts of cereal straw is returned across all of China's agricultural regions, cereal yields would increase by an average of 2.84 and

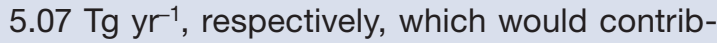
ute to achieving the increasing yield requirements of China.
\end{abstract}

H. Zhao, B. Sun, F. Lu, G. Zhang, X. Wang, and Z. Ouyang, State Key Lab. of Urban and Regional Ecology, Research Center for Eco-Environmental Sciences, Chinese Academy of Sciences, Beijing 100085, China; H. Zhao and B. Sun, Univ. of Chinese Academy of Sciences, Beijing 100049, China. Received 2 Sep. 2014. Accepted 20 Jan. 2015. *Corresponding author (feilu@rcees.ac.cn).

Abbreviations: AMP, annual mean precipitation; AMT, annual mean temperature; $\ln (R)$, response ratio; NBSPRC, National Bureau of Statistics of the People's Republic of China; NT, no tillage; PT, plowing tillage; RT, rotary tillage; SI, straw incorporation; SOC, soil organic carbon; SR, straw removal.

O HINA has $7 \%$ of the arable land, $6 \%$ of the water resources in the world, and feeds $22 \%$ of the world population (Zhang et al., 2011); therefore, food security is a top priority in China. It is estimated that the Chinese population will peak in 2033 at 1.47 billion. If annual per-capita food consumption requirement is at 400 to $450 \mathrm{~kg}$ (Feng, 2007), China will need 589 to $663 \mathrm{Tg}$ of cereals to feed its population in 2033, equivalent to an increase of 0.81 to $1.46 \%$ per year from now. During the past five decades, China has adopted a series of agricultural practices and biotechnology methods to enhance cereal yield (Zhu and Chen, 2002; Zhou et al., 2007; Xue et al., 2013). Cereal production has increased 3.2 -fold, with approximately $50 \%$ of this increase due to higher application rates of synthetic fertilizers (Wang and Xiao, 2008).

Nevertheless, due to many constraints, increases in crop production have lagged since the middle of the 1990s, with an annual increase of only $0.60 \%$ (Zhang et al., 2011). To maximize crop yields, synthetic fertilizer rates have greatly increased since the

Published in Crop Sci. 55:1773-1781 (2015).

doi: 10.2135/cropsci2014.09.0599

(C) Crop Science Society of America | 5585 Guilford Rd., Madison, WI 53711 USA

All rights reserved. No part of this periodical may be reproduced or transmitted in any form or by any means, electronic or mechanical, including photocopying, recording, or any information storage and retrieval system, without permission in writing from the publisher. Permission for printing and for reprinting the material contained herein has been obtained by the publisher. 
1990s, but, unfortunately, synthetic fertilizer application induced-yield enhancement has declined rapidly (Zhu and Chen, 2002). Generally, under high $\mathrm{N}$ fertilizer application, 5 to $15 \%$ of the $\mathrm{N}$ fertilizer is transformed into yield (Erisman et al., 2007) and the remaining $\mathrm{N}$ becomes either greenhouse gases (Smith et al., 2008) or pollution sources (Zhu and Chen, 2002; Bouraoui and Grizzetti, 2014). Additionally, the per-capita arable land area in China is only 0.1 ha, which is one-seventh of that in the United States and less than half of the world's average (Wang et al., 2009). Furthermore, the quality of the arable land has seriously degraded, with over $60 \%$ having some factors that limited yield increment (Zhao et al., 2006). Above all, an annual increase of 0.81 to $1.46 \%$ yield will be a great challenge in the next $20 \mathrm{yr}$, and in addition to synthetic fertilizers, China needs other valid methods to achieve greater production from the limited arable land to ensure food security.

China produces approximately $820 \mathrm{Tg}$ of crop straw, which represents 1.3 times the total crop yield (Liu et al., 2008b; STEMOA, 2010). The cereal crops rice, maize (Zea mays L.) and wheat (Triticum aestivum L.) are responsible for $75 \%$ of the total crop straw (STEMOA, 2010). It was estimated that $1 \mathrm{t}$ of cereal straw contains 12 to $20 \mathrm{~kg}$ of $\mathrm{N}, 1$ to $4 \mathrm{~kg}$ of $\mathrm{P}, 7$ to $30 \mathrm{~kg}$ of $\mathrm{K}$ (Lal, 2004), and the burning of straw results in the loss of almost all the $\mathrm{C}$ and N (Dobermann and Fairhurst, 2000; Yadvinder-Singh et al., 2004). Although straw contains abundant nutrients, only $22 \%$ of straw is used as fertilizer in soils, and most is discarded or directly burnt in the field (Lu et al., 2010).

China's cropland has characteristic double-cropping systems (on $70 \%$ of the arable land), and repetitively harvesting crops can decrease soil quality. Thus, the National Modern Agriculture Development Plan, 2011-2015 (Ministry of Agriculture-PRC, 2011) stressed comprehensive use of straws to protect the soil environment and increase crop yield. There have been numerous recent investigations about SI effects on cereal yield across China, with both positive and negative effects observed (Tan et al., 2009; Zhang et al., 2014). Up to now, only the response of yield to SI in rice paddies has been systematically investigated on a large scale (Dawe et al., 2003; Huang et al., 2013). Wheat and maize account for $60 \%$ of China's total cereal yield, and feed 730 million of the population, nevertheless, few papers have synthesized assessments of how these yields respond to SI. China has a great diversity of climates, soil types, and cropping systems, and metaanalysis can synthesize such data from multiple locations, with temporal variability in results, and draw consistent conclusions across studies (Gurevitch and Hedges, 1999). Thus, our overall objectives in this study are to (i) investigate how certain factors (e.g., SI amount, tillage type, and cropping system) influence the response of cereal (maize, wheat, and rice) yield to SI and (ii) estimate cereal yield increase with adoption of SI management in China.

\section{MATERIALS AND METHODS Data Collection}

An exhaustive literature survey was performed by searching the ISI-Web of Science, Chinese Core Journal databases (CNKI and Wanfang databases) and Google Scholar (Google Inc.) for peer-reviewed articles published before June 2014 and containing the keywords straw, yield, rice, maize, wheat, and their combinations. Studies had to meet the following specific criteria: (i) annual cereal yield values were reported within the paper; (ii) field experiments were included, but pot experiments, agroforestry systems, or vegetable land were excluded; (iii) experimental periods were $>3 \mathrm{yr}$; and (iv) rice, maize, and wheat were included because they are the most common crops cultivated in China and they produce $75 \%$ of the total straw (STEMOA, 2010). A total of 64 papers (Supplemental Table S1), consisting of 142 paired cereal yield data met our inclusion criteria. The experimental field distribution is shown in Fig. 1.

The means, standard deviations, and replications of cereal yields for straw removal (SR) and SI were taken from the published literature, including tables, texts, and figures. The data from figures were extracted by using digitizing software (GRAFULA 3 v.2.10, Wesik SoftHaus). Ancillary information on the soil basic chemical and physical properties of the experimental sites $(0-20 \mathrm{~cm}$ depth) was collected. Additionally, the agricultural management combined with SI such as tillage treatment, straw amount, cropping system, experimental site, and duration were also extracted from the articles.

To explain the variations in response of cereal yield to SI, the paired measurements were further categorized according to (i) tillage type: no tillage (NT), plowing tillage (PT), and rotary tillage (RT); (ii) cropping system: rice-rice, wheat-rice, wheatmaize, and single maize, wheat, or rice (single); (iii) experiment region: northeast (lower annual mean temperature [AMT], with single cropping), north (warm, with double upland cropping), northwest (warm and dry, with single cropping), and south (hot and moist, with double cropping); (iv) soil texture: fine- and coarse-textured; (v) experimental duration $(<10$ and $>10 \mathrm{yr}$ ); and (vi) straw amount: half and full amounts of SI management.

\section{Analysis}

A meta-analysis was conducted to detect the response of cereal yield to SI. A response ratio, $\ln (R)$, or the natural $\log$ of the ratio of the mean value of a concerned variable in SI management to that in SR, was used to represent the magnitude of the effects of SI as below (Rosenberg et al., 2000):

$$
\ln (R)=\ln \left(\frac{\overline{X_{\mathrm{SI}}}}{\overline{X_{\mathrm{SR}}}}\right)
$$

Where, $\overline{X_{\mathrm{SI}}}$ and $\overline{X_{\mathrm{SR}}}$ are the mean yield values of SI and SR treatments, respectively. This method estimates the effect as a proportionate change resulting in SI manipulation, and calculated as $(\mathrm{R}-1) \times 100 \%$ (Curtis and Wang, 1998; Feng et al., 2008). Negative percentage changes indicate an inhibitory effect of SI, and positive values indicate an increase of a variable in response to SI. 


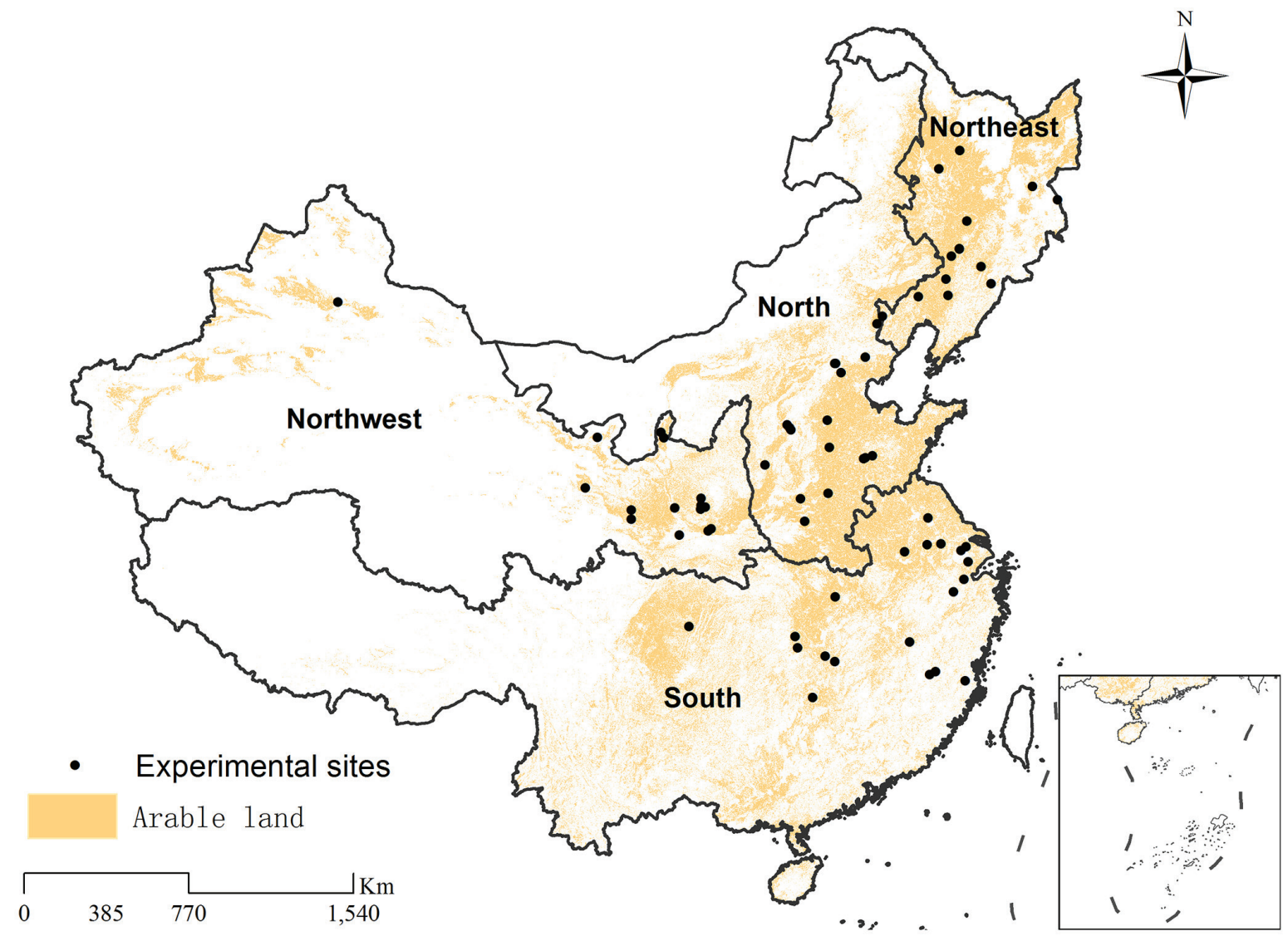

Figure 1. The distribution of experimental straw study sites in China.

An unweighted meta-analysis was adopted, as most of the collected papers did not provide a measure of variance for cereal yield (Gurevitch and Hedges, 1999; Rosenberg et al., 2000). Following the techniques of Curtis and Wang (1998), the metaanalysis was conducted using a meta-analytical software package METAWIN 2.1.3.4 (Rosenberg et al., 2000). Random-effects models allow comparisons among categories in a framework similar to ANOVA, and thus we adopted a random-effects categorical summary analysis to compare the variances of the different categorical groups. We defined statistical significance as $p<0.05$ under between-group heterogeneity $\left(Q_{b}\right)$. Confidence limits around the effect size were calculated using a bootstrap method with 4999 interactions (Rosenberg et al., 2000). In cases where $95 \%$ confidence intervals did not overlap zero, a significant SI-induced response was considered (Curtis and Wang, 1998).

A stepwise regression analysis was used to analyze the relationship between $\ln (R)$ and soil nutrients, AMT, and annual mean precipitation (AMP), using SPSS version 10 (SPSS Inc, 2011). Regression equations were regarded as significant, if $p<0.05$.

\section{RESULTS}

\section{Response of Cereal Yield to Straw Incorporation across Different Soil Environments}

Of 142 comparisons, cereal yields were enhanced in 92\% (131 comparisons) and reduced in 8\% (11 comparisons) of locations under SI management. Overall, cereal yields were significantly higher (7\%) for locations under SI management compared with SR management (Fig. 2). Results showed significant between-group heterogeneity among experimental regions, soil texture, and cropping systems (Table 1). Averaged annual yield differences in SI compared with SR indicated a 12 and 8\% increases in the northwest and north regions, respectively, which are significantly higher than those in the south $(6 \%)$ and northeast (4\%) regions (Fig. 2). The yield increase with SI was significantly greater in coarse-textured (9\%) than in fine-textured soils (6\%). Wheat-maize, single, and wheat-rice rotations resulted in higher yield increments than for rice-rice (3\%). Experimental durations of $<10$ and $>10$ yr resulted in cereal yield increase with SI of 6 and $8 \%$, respectively, but with no significant difference between them (Table 1). The $\ln (R)$ across all the studies exponentially decreased with increases in initial soil chemical properties in the top $20 \mathrm{~cm}$ of soil (crop available $\mathrm{N}$ and total K; Fig. 3a,b). In the northwest region, there was a positive relationship of $\ln (R)$ with AMT (Fig. 4b-1) and with AMP (Fig. 4b-2). In other regions, there was no pronounced relationship between $\ln (R)$ and AMT and AMP (Fig. 4a-1, a-2, c-1, c-2, d-1, d-2). 


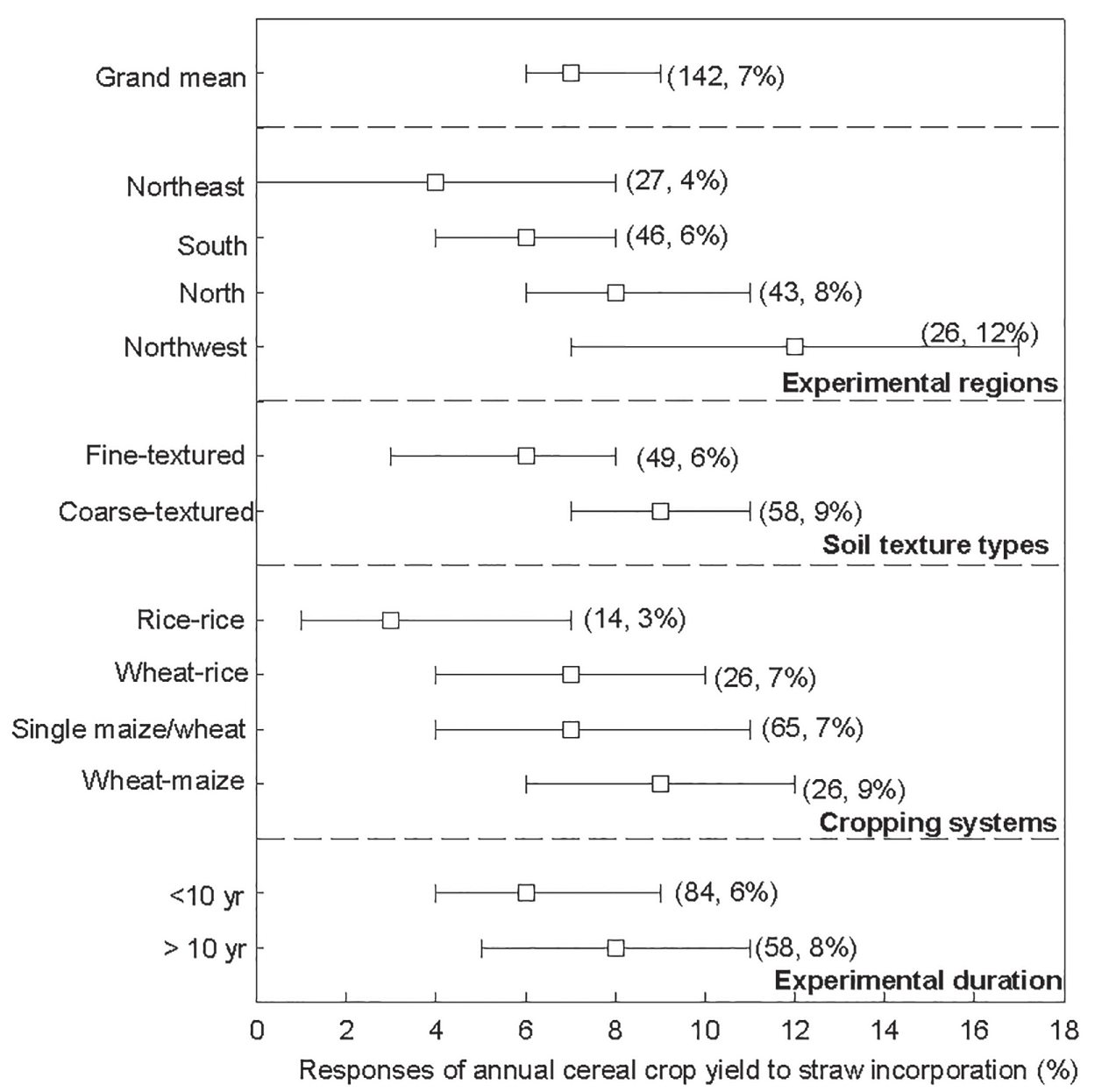

Figure 2. Response of annual cereal crop yield to straw incorporation under different experimental regions, soil texture types, and cropping systems. The square and the horizontal line represent the mean and range of cereal yield response to straw incorporation at 95\% confidence interval; the number and percentage value in parentheses indicate the number of paired trials and the percentage increase.

Table 1. Effects of straw incorporation on between-group heterogeneity for cereal yield.

\begin{tabular}{|c|c|c|c|c|c|c|c|}
\hline & $n$ & Tillage & Cropping system & Regions & Texture & $\begin{array}{l}\text { Experiment } \\
\text { duration }\end{array}$ & Straw amount \\
\hline Yield & 142 & $6.60^{\star}$ & $6.35^{\star}$ & $7.63^{\star}$ & $3.62^{\star}$ & 3.31 & $3.66^{*}$ \\
\hline
\end{tabular}

* Significant at the 0.05 probability level.

\section{Response of Cereal Yield to Straw Incorporation under Different Agricultural Management Practices}

Overall, the effects of SI on cereal yield varied significantly with different tillage treatments and straw amount (Table 1). For SI compared with SR, the enhancement of cereal yield in RT (12\%) was significantly higher than that for PT (7\%) and NT (6\%), and the full amount of SI management (9\%) resulted in a greater cereal yield increment than the half amount (6\%). The response of cereal yield to straw amount also varied in different regions (Fig. 5a-d); the greatest difference between full and half amounts of SI was for the northwest region, with 18 and $6 \%$ of the yield increases, respectively (Fig. 5a).

\section{DISCUSSION}

\section{How Would Straw Incorporation Increase Cereal Yield in China?}

In China, an average 7\% increase in cereal yield after adoption of SI could be induced by the following several mechanisms. First, SI could significantly improve SOC ( $\mathrm{Lu}$ et al., 2009; Zhao et al., 2014), and SOC is of fundamental importance to soil fertility and directly affects crop yield (Lal, 2004, 2010). In the present study, of a total of 142 comparisons of cereal yield, 88 paired comparisons included SOC storage due to SI management. Regression analysis revealed a significant linear relationship between $\ln (R)$ of cereal yield and $\ln (R)$ of SOC storage $\left\{\ln (R)_{\text {cereal_yield }}=0.03\right.$ $\left.+0.35\left[\ln (R)_{\text {SOC_storage }}\right] ; R^{2}=0.38 ; p<0.01\right\}$. According to the ratio of SOC change to cereal yield change after adoption of SI management, we found $1 \mathrm{t} \mathrm{ha}^{-1}$ of SOC 

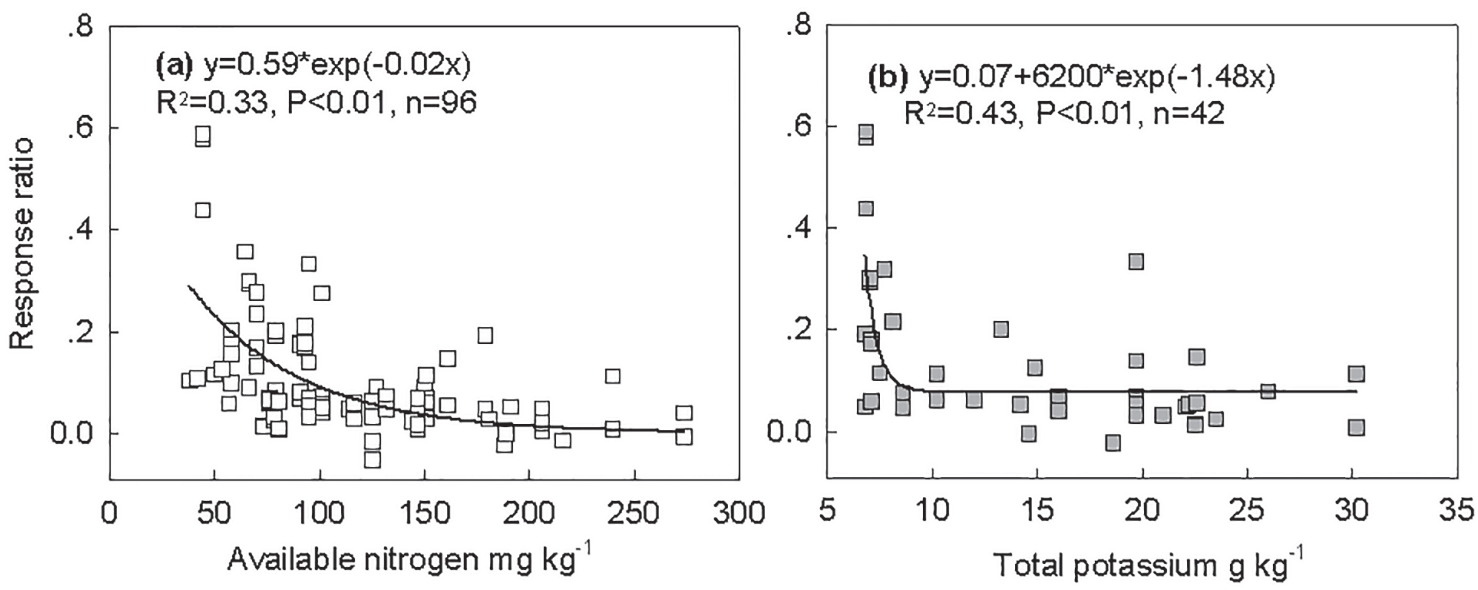

Figure 3. The relationship between response ratio and initial crop available $\mathrm{N}$ and total $\mathrm{K}(0-20 \mathrm{~cm}$ depth).

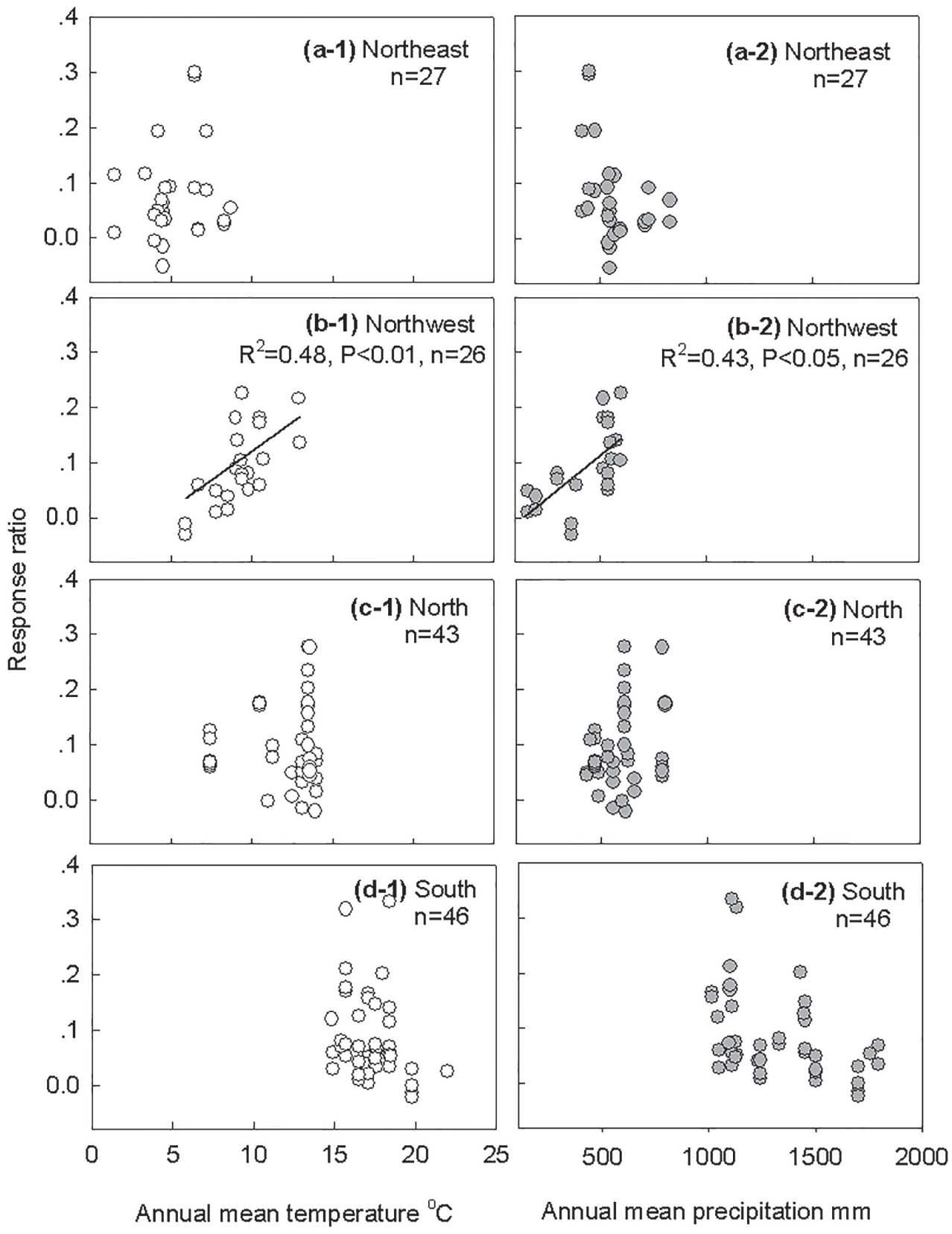

Figure 4. The relationship between response ratio and annual mean temperature and precipitation in different experimental regions. 


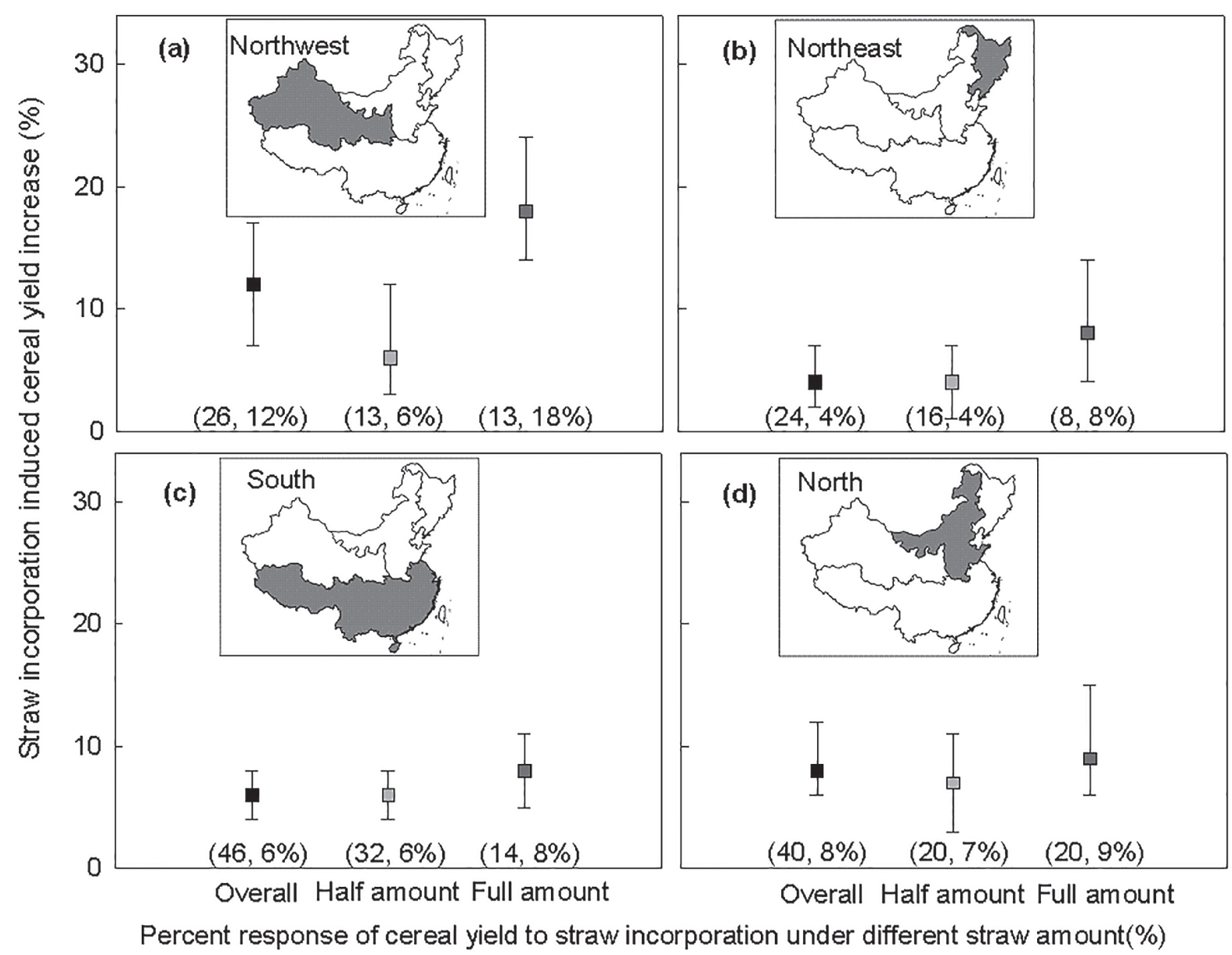

Figure 5. Response of annual cereal crop yield to different straw amounts in different experimental regions. The square and vertical line represent the mean and range of cereal yield response to straw incorporation at 95\% confidence interval; the number and percentage value in parentheses indicate the number of paired trials and the percentage increase. Half amount, and full amount in the horizontal line, respectively, represent the incorporation of half amount of the straw in each hectare of cropland and and incorporation of full amount of the straw in each hectare of cropland. Overall in the $x$-axis represents the overall cereal yield increase between half and full amount.

storage increment could increase cereal yield by $44 \mathrm{~kg} \mathrm{ha}^{-1}$. Second, SI can substantially improve soil physical properties (e.g., soil aggregation and bulk density) (Powlson et al., 2011) and soil temperature (Ramakrishna et al., 2006) and increase soil water retention, especially in dry areas and dry years (Malhi et al., 2011a; Zhang et al., 2014). Third, cereal straw contains abundant essential nutrients required for crop growth. Using the cereal production data from 2010 (National Bureau of Statistics of the People's Republic of China [NBSPRC], 2010), straw/grain ratio (Han et al., 2002) and straw nutrient content (National Center for Services and Popularization of Agricultural Techniques, 1999), we estimated that cereal straw in China produced (all in Tg) 230 of C, 5 of N, 0.72 of P, and 10 of $\mathrm{K}$. The $\mathrm{N}$ and $\mathrm{P}$ amounts in cereal straw account for 21 and $9 \%$ of the application of chemical $\mathrm{N}$ and $\mathrm{P}$ fertilizers, respectively, while the amount of $\mathrm{K}$ in cereal straw is 1.8 times that in $\mathrm{K}$ fertilizer applied in China (NBSPRC, 2010). Straw incorporation management could improve the $\mathrm{N}$-supplying power of soil (Malhi et al., 2011a,b). Relevant studies showed that increasing SI amounts in China from 15 to 90\% would increase the $\mathrm{N}$ mineralization rates by 10 to $25 \%$ in the following year, thus reducing the need for synthetic $\mathrm{N}$ fertilizers (Li et al., 2003). Straw K could even substitute for the same amount of synthetic K fertilizers (Lao et al., 2003).

Of 142 data pairs, 11 data pairs showed cereal yields were suppressed by SI compared with SR management; all of the 11 data pairs were distributed in the regions with rich SOC and soil nutrient. Additionally, this might be due to weed infestation or insect damage under SI (Liu et al., 2010b). However, no consensus has yet been reached on whether SI generally stimulates or suppresses weed infestation and insect damage (Ramakrishna et al., 2006; Liu et al., 2010b; Huang et al., 2014). Furthermore, SI technology has been researched for $30 \mathrm{yr}$ in China, and a series of sound SI techniques have been formed in different climate zones and cropping systems (Liu et al., 2001; Bi et al., 2008; Liu et al., 2008a). Moreover, previous studies showed that SI promoted cereal yield over the long rather than the short term (Takahashi et al., 2003); therefore, SI should be an effective practice to enhance crop yield in China in the long run. 
Table 2. Cereal yield increase potential in different experimental regions and whole China.

\begin{tabular}{|c|c|c|c|c|c|c|c|}
\hline \multirow[b]{2}{*}{$\begin{array}{l}\text { Experimental } \\
\text { region }\end{array}$} & \multirow[b]{2}{*}{$\begin{array}{l}\text { Total } \\
\text { cereal yield } \\
\text { in } 2010\end{array}$} & \multicolumn{3}{|c|}{$\begin{array}{c}\text { Scenario I } \\
\text { (half amount of straw incorporation) }\end{array}$} & \multicolumn{3}{|c|}{$\begin{array}{c}\text { Scenario II } \\
\text { (full amount of straw incorporation) }\end{array}$} \\
\hline & & $\begin{array}{l}\text { Yield } \\
\text { increase } \\
\text { ratio }\end{array}$ & $\begin{array}{l}\text { Yield } \\
\text { increase }\end{array}$ & $\begin{array}{c}\text { Mean } \\
\text { experimental } \\
\text { duration }\end{array}$ & $\begin{array}{l}\text { Yield } \\
\text { increase } \\
\text { ratio }\end{array}$ & $\begin{array}{l}\text { Yield } \\
\text { increase }\end{array}$ & $\begin{array}{c}\text { Mean } \\
\text { experimental } \\
\text { duration }\end{array}$ \\
\hline & $\mathrm{Tg}$ & $\%$ & $\mathrm{Tg}$ & $\mathrm{yr}$ & $\%$ & $\mathrm{Tg}$ & $\mathrm{yr}$ \\
\hline Northeast & 86.16 & 4 & 3.44 & 9 & 8 & 6.89 & 9 \\
\hline Northwest & 32.69 & 6 & 1.96 & 12 & 18 & 5.88 & 8 \\
\hline North & 152.84 & 7 & 10.69 & 10 & 9 & 13.76 & 9 \\
\hline South & 224.69 & 6 & 13.48 & 9 & 8 & 17.97 & 10 \\
\hline Whole China & 496.38 & & 29.57 & & & 44.51 & \\
\hline
\end{tabular}

\section{Meta-Analysis for Cereal Yield Response to Straw Incorporation}

This study analyzed the response of cereal yield to SI, which varied greatly with experimental region, cropping system, soil nutrient level, soil texture, straw amount, climate, and tillage type. The critical contributing factors can be summarized in two capacities of SI: retaining soil water (Ramakrishna et al., 2006; Li et al., 2012; Zhang et al., 2014) and increasing SOC (Lu et al., 2009; Malhi et al., 2011b; Zhao et al., 2014).

Retaining soil water led to increases in cereal yields mainly in areas with low water availability. The northwest region is the driest area in China, with an average AMP of 200 to $600 \mathrm{~mm}$, and over $90 \%$ of the cropland receives no irrigation (Liu et al., 2010a). A field experiment in the Loess Plateau of the northwest revealed that SI showed the same capacity for storing soil water, as did mulching with plastic film or biodegradable film (Li et al., 2012). Due to rapid drying in coarse-textured soils, Arora et al. (2011) demonstrated that SI management would result in greater yield increments in coarse-textured compared with finetextured soils, which was consistent with our results.

Soil organic C is the foundation and core of soil fertility, and increasing SOC results in enhancing of cereal yields mainly in areas with depleted soil nutrients and SOC (Lal, 2004). Unlike other upland cropping regions (northwest and north regions), the northeast region is associated with higher SOC, lower AMT, and single cropping (Pan and Zhao, 2005; Lu et al., 2009). The power of SI to increase yield was not evident under lower straw decomposition rates and SOC-rich northeast soils. Fine-textured and rice-rice cropping soils generally have greater SOC compared with coarse-textured and other cropping (i.e., wheat-rice, wheat-maize, and single) soils (Plante et al., 2006; Huang et al., 2012); therefore, they have lower capacity to enhance production (Lal, 2010). Recent reports verified that, due to improving soil physical structure, RT combined with SI management resulted in increased cereal yields (Zhao et al., 2013; Guan et al., 2014). In the present study, there was a decreasing $\ln (R)$ of cereal yield with increases in initial crop available $\mathrm{N}$ and total $\mathrm{K}$. This might suggest that in originally nutrient-poor regions, SI management benefited uptake of nutrient elements (Sheldrick et al., 2003; Guan et al., 2014) and caused greater yield increases. At an Asia-scale, Dawe et al. (2003) concluded that organic amendments might not improve grain yield in rice-rice and rice-wheat cropping systems but would be profitable as complements to synthetic fertilizer. Therefore, SI might not always increase cereal yield, especially in soils containing higher levels of SOC and nutrients.

\section{Estimated Cereal Yield Increase in China}

In recent years, the Chinese government has made great efforts to prohibit straw field burning and encourage SI (Lu et al., 2010). As a result, the techniques of full amount of crop SI are popularized across the whole of China, especially in the northwest and north regions, for keeping soil water content (Li et al., 2012). However, taking into account the labor costs and straw decomposition rate for SI practices, a number of regions still implement half amount of crop SI (Bi et al., 2008), particularly in the north, south (the doublecrop regions), and northeast regions. Therefore, two scenarios were considered in the present study: incorporation in each hectare of cropland of half- of the amount of the straw (Scenario I) and full amount of the straw (Scenario II). By multiplying the yield increase ratio by total cereal yield in 2010, the cereal yield increase potential in different experimental regions could be obtained (Table 2). It could be expected that on the national scale, total cereal yield across the 9-yr period (as the data was drawn from the field experiments that lasted for 8 to $12 \mathrm{yr}$ with an average of 9 yr) would increase by 29.59 and $44.51 \mathrm{Tg}$ (Table 2), or 2.84 and 5.07 $\mathrm{Tg} \mathrm{yr}^{-1}$, respectively, if half amount (Scenario I) or full amount of SI (Scenario II) management is implemented. These increase potentials correspond to 0.57 and $1.02 \%$ of the total cereal yield in 2010 (NBSPRC, 2010). However, it is noteworthy that, as for SOC saturation mechanisms (Six et al., 2002; Zhao et al., 2014), SI-induced yield increase is not constant, especially in nutrient-rich regions. Despite this, SI is still a valid management for ameliorating soil quality and providing guarantees for yield security (Powlson et al., 2011), especially in China. Feasible management strategy 
and policy that ensure stable cereal yield improvement are needed in the future.

\section{CONCLUSIONS}

This study demonstrated that, compared with SR, SI significantly increase cereal yield by $7 \%$ over all of China across the 9 -yr period. When evaluating the magnitude of the effect of SI on cereal yield, it is critical to consider such factors as experimental site, cropping system, straw amount, soil circumstances, climate, and tillage type. Our results revealed that response of cereal yield to SI was greater in areas experiencing water deficits and low levels of nutrient elements and SOC. Additionally, we estimated that an increase of $1 \mathrm{tha}^{-1}$ of SOC storage could increase cereal yield by $44 \mathrm{~kg} \mathrm{ha}^{-1}$. If half or full amount of SI is implemented, there would be a respective 2.84 and $5.07 \mathrm{Tg} \mathrm{yr}^{-1}$ of cereal yield increase, corresponding to 0.57 and $1.02 \%$ of the cereal yield in 2010 . Therefore, SI management should be encouraged for its contribution to increasing cereal yield in China.

\section{Acknowledgments}

This work was supported by the National Natural Science Foundation of China (Grant No. 71003092), the Strategic Priority Research Program-Climate Change: Carbon Budget and Relevant Issues of the Chinese Academy of Sciences (Grant No. XDA05050602), and the Ministry of Science and Technology of the People's Republic of China (Grant No. 2010CB83350403). We also acknowledge Zhaozhong Feng for the assistance about the use of meta-analysis.

\section{References}

Arora, V.K., C.B. Singh, A.S. Sidhu, and S.S. Thind. 2011. Irrigation, tillage and mulching effects on soybean yield and water productivity in relation to soil texture. Agr. Water Manage. 98:563-568. doi:10.1016/j.agwat.2010.10.004

Bi, Y., J. Kou, and D. Wang. 2008. Comprehensive utilization technology of straw resources in China. (In Chinese.) Chinese Agricultural Science and Technology Publishing House. Beijing, PRC.

Bouraoui, F., and B. Grizzetti. 2014. Modelling mitigation options to reduce diffuse nitrogen water pollution from agriculture. Sci. Total Environ. 468-469:1267-1277. doi:10.1016/j.scitotenv.2013.07.066

Curtis, P.S., and X. Wang. 1998. A meta-analysis of elevated $\mathrm{CO}_{2}$ effects on woody plant mass, form, and physiology. Oecologia 113: 299-313. doi:10.1007/s004420050381

Dawe, D., A. Dobermann, J.K. Ladha, R.L. Yadav, L. Bao, R.K. Gupta, P. Lal, G. Panaullah, O. Sariam, Y. Singh, A. Swarup, and Q.X. Zhen. 2003. Do organic amendments improve yield trends and profitability in intensive rice systems? Field Crops Res. 83:191-213. doi:10.1016/S0378-4290(03)00074-1

Dep. of Science and Technology and Education, Ministry of Agriculture of the People's Republic of China (STEMOA). 2010. Survey and access report of national crop straw source. (In Chinese.) http://d.wanfangdata.com.cn/Periodical_nygcjs201102002.aspx (accessed 13 Sept. 2013).

Dobermann, A., and T. Fairhurst. 2000. Rice: Nutrient disorders and nutrient management. International Rice Research Institute, Los Baños, Philippines.
Erisman, J.W., A. Bleeker, J. Galloway, and M.S. Sutton. 2007. Reduced nitrogen in ecology and the environment. Environ. Pollut. 150:140-149. doi:10.1016/j.envpol.2007.06.033

Feng, Z. 2007. Future food security and arable land guarantee for population development in China. (In Chinese with English abstract.) Popul. Res. 31:15-29.

Feng, Z.Z., K. Kobayashi, and E.A. Ainsworth. 2008. Impact of elevated ozone concentration on growth, physiology, and yield of wheat (Triticum aestivum L.): A meta-analysis. Glob. Change Biol. 14:2696-2708. doi:10.1111/j.1365-2486.2008.01673.x

Guan, D., M.M. Al-Kaisi, Y. Zhang, L. Duan, W. Tan, M. Zhang, and Z. Li. 2014. Tillage practices affect biomass and grain yield through regulating root growth, root-bleeding sap and nutrients uptake in summer maize. Field Crops Res. 157:89-97. doi:10.1016/j.fcr.2013.12.015

Gurevitch, J., and L.V. Hedges. 1999. Statistical issues in ecological meta-analyses. Ecology 80:1142-1149. doi:10.1890/00129658(1999)080[1142:SIIEMA]2.0.CO;2

Han, L., Q. Yan, X. Liu, and J. Hu. 2002. Straw resources and their utilization in China. (In Chinese with English abstract.) Transaction of the CSAE. 18: 87-91.

Huang, S., Y. Sun, and W. Zhang. 2012. Changes in soil organic carbon stocks as affected by cropping systems and cropping duration in China's paddy fields: A meta-analysis. Clim. Change 112:847858. doi:10.1007/s10584-011-0255-x

Huang, S., L. Wang, L. Liu, Q. Fu, and D. Zhu. 2014. Nonchemical pest control in China rice: A review. Agron. Sustain. Dev. 34:275291. doi:10.1007/s13593-013-0199-9

Huang, S., Y. Zeng, J. Wu, Q. Shi, and X. Pan. 2013. Effect of crop residue retention on rice yield in China: A meta-analysis. Field Crops Res. 154:188-194. doi:10.1016/j.fcr.2013.08.013

Lal, R. 2004. Soil C sequestration impacts on global climatic change and food security. Science 304:1623-1627. doi:10.1126/science.1097396

Lal, R. 2010. Beyond Copenhagen: Mitigating climate change and achieving food security through soil carbon sequestration. Food Sec. 2:169-177. doi:10.1007/s12571-010-0060-9

Lao, X.R., W.D. Sun, Z. Wang, Y.R. Hao, and C.A. Zhang. 2003. Effect of matching use of straw and chemical fertilizer on soil fertility. (In Chinese with English abstract.) Acta Pedologica Sinca. 40:618-623.

Li, C.S., Y.H. Zhuang, S. Frolking, J. Galloway, R. Harriss, B. Moore, D. Schimel, and X. Wang. 2003. Modeling soil organic carbon change in croplands of China. Ecol. Appl. 13:327-336. doi:10.1890/1051-0761(2003)013[0327:MSOCCI]2.0.CO;2

Li, R., X. Hou, Z. Jia, Q. Han, and B. Yang. 2012. Effects of rainfall harvesting and mulching technologies on soil water, temperature, and maize yield in Loess Plateau region of China. Soil Res. 50:105-113. doi:10.1071/SR12232

Liu, D., B. Fan, and M. Gong. 2008a. The role of technology of straw returning to field in developing ecological agriculture. (In Chinese with English abstract.) Chinese Agric. Sci. Bull. 24:404-407.

Liu, E.K., C.G. Yan, X.R. Mei, W.Q. He, S.H. Bing, L.P. Ding, Q. Liu, S. Liu, and T.L. Fan. 2010a. Long-term effect of chemical fertilizer, straw, and manure on soil chemical and biological properties in northwest China. Geoderma 158:173-180. doi:10.1016/j. geoderma.2010.04.029

Liu, F., Z. Gong, X. Ma, and N. Jia. 2010b. Effect of rice stalks back to field on the occurrence of disease. (In Chinese with English abstract.) Heilj. Agri. Sci. 8:75-78.

Liu, H., G.M. Jiang, H.Y. Zhuang, and K.J. Wang. 2008b. Distribution, utilization structure and potential of biomass resources 
in rural China: With special references of crop residues. Renew. Sustain. Energy Rev. 12:1402-1418. doi:10.1016/j.rser.2007.01.011 Liu, X., W. Gao, and W. Zhu. 2001. Mechanism and techniques of straw returning. (In Chinese.) China Agriculture Press. Beijing, PRC.

Lu, F., X.K. Wang, B. Han, Z. Ouyang, X. Duan, H. Zheng, and H. Miao. 2009. Soil carbon sequestrations by nitrogen fertilizer application, straw return and no-tillage in China's cropland. Glob. Change Biol. 15:281-305. doi:10.1111/j.1365-2486.2008.01743.x

Lu, F., X.K. Wang, B. Han, Z. Ouyang, and H. Zheng. 2010. Modeling the greenhouse gas budget of straw returning in China. Ann. N. Y. Acad. Sci. 1195:107-130. doi:10.1111/j.1749-6632.2009.05408.x Malhi, S.S., M. Nyborg, E.D. Solberg, M. Dyck, and D. Puurveen. 2011a. Improving crop yield and N uptake with long-term straw retention in two contrasting soil types. Field Crops Res. 124:378391. doi:10.1016/j.fcr.2011.07.009

Malhi, S.S., M. Nyborg, E.D. Solberg, B. McConkey, M. Dyck, and D. Puurveen. 2011b. Long-term straw management and $N$ fertilizer rate effects on quantity and quality of organic $\mathrm{C}$ and $\mathrm{N}$, and some chemical properties in two contrasting soils in western Canada. Biol. Fertil. Soils 47:785-800. doi:10.1007/s00374-011-0587-8

Ministry of Agriculture-PRC. 2011. National modern agriculture development plan 2011-2015. http://english.agri.gov.cn/hottopics/five/ (accessed 12 Apr. 2013).

National Bureau of Statistics of the People's Republic of China (NBSPRC). 2010. China statistical yearbook, electronic edition. China Statistics Press, Beijing.

National Center for Services and Popularization of Agricultural Techniques. 1999. The organic fertilizer of China. (In Chinese.) China Agriculture Press, Beijing, China. .

Pan, G., and Q. Zhao. 2005. Study on evolution of organic carbon stock in agricultural soils of China: Facing the challenge of global change and food security. (In Chinese with English abstract.) Adv. Earth Sci. 20:384-392.

Plante, A.F., R.T. Conant, C.E. Stewart, K. Paustian, and J. Six. 2006. Impact of soil texture on the distribution of soil organic matter in physical and chemical fractions. Soil Sci. Soc. Am. J. 70:287-296. doi:10.2136/sssaj2004.0363

Powlson, D.S., M.J. Glendining, K. Coleman, and A.P. Whitmore. 2011. Implications for soil properties of removing cereal straw: Results from long-term studies. Agron. J. 103:279-287. doi:10.2134/agronj2010.0146s

Ramakrishna, A., H.M. Tamb, S.P. Wani, and T.D. Long. 2006. Effect of mulch on soil temperature, moisture, weed infestation and yield of groundnut in northern Vietnam. Field Crops Res. 95:115-125. doi:10.1016/j.fcr.2005.01.030

Rosenberg, M.S., D.C. Adams, and J. Gurevitch. 2000. Metawin: Statistical software for meta-analysis, version 2.1. Sinauer Associates, Inc, Sunderland, MA, USA.

Sheldrick, W.F., J.K. Syers, and J. Lingard. 2003. Soil nutrient audits for China to estimate nutrient balances and output/input relationships. Agric. Ecosyst. Environ. 94:341-354. doi:10.1016/S01678809(02)00038-5

Six, J., R.T. Conant, E.A. Paul, and K. Paustian. 2002. Stabilization mechanisms of soil organic matter: Implications for C saturation of soils. Plant Soil 241:155-176. doi:10.1023/A:1016125726789

Smith, P., D. Martino, Z.C. Cai, D. Gwary, H. Janzen, P. Kumar, B. McCarl, S. Ogle, F. O’Mara, C. Rice, B. Scholes, O. Sirotenko, M.
Howden, T. McAllister, G. Pan, V. Romanenkov, U. Schneider, S. Towprayoon, M. Wattenbach, and J. Smith. 2008. Greenhouse gas mitigation in agriculture. Phil. Trans. R. Soc. B. 363:789-813. doi:10.1098/rstb.2007.2184

SPSS Inc. 2011. SPSS version 10.0. SPSS Inc., Chicago, IL.

Takahashi, S., S. Uenosono, and S. Ono. 2003. Short- and long-term effects of rice straw application on nitrogen uptake by crops and nitrogen mineralization under flooded and upland conditions. Plant Soil 251:291-301. doi:10.1023/A:1023006304935

Tan, D., J. Jin, S. Huang, and Z. Chen. 2009. Study on effect of longterm application of $\mathrm{K}$ fertilizer and returning straw to soil on soil nutrient and wheat yield in the regions of Castanozem. (In Chinese with English abstract.) Agric. Res. Arid Areas. 27:194-198.

Wang, H., M. Zhang, and Y. Cai. 2009. Problems, challenges, and strategic options of grain security in China. Adv. Agron. 103:101147. doi:10.1016/S0065-2113(09)03003-X

Wang, Z., and H. Xiao. 2008. Analysis of the contribution of fertilizer application on cereal yield increase. (In Chinese with English abstract.) Issus. Agric. Econ. 8:65-68.

Xue, Y., H. Duan, L. Liu, Z. Wang, J. Yang, and J. Zhang. 2013. An improved crop management increases grain yield and nitrogen and water use efficiency in rice. Crop Sci. 53:271-284. doi:10.2135/ cropsci2012.06.0360

Yadvinder-Singh, B.S., J.K. Ladha, C.S. Khind, R.K. Gupta, O.P. Meelu, and E. Pasuquin. 2004. Long-term effects of organic inputs on yield and soil fertility in the rice-wheat rotation. Soil Sci. Soc. Am. J. 68:845-853. doi:10.2136/sssaj2004.8450

Zhang, F., Z. Cui, M. Fan, W. Zhang, X. Chen, and R. Jiang. 2011. Integrated soil-crop system management: Reducing environmental risk while increasing crop productivity and improving nutrient use efficiency in China. J. Environ. Qual. 40:1051-1057. doi:10.2134/jeq2010.0292

Zhang, P., T. Wei, Z. Jia, Q. Han, and X. Ren. 2014. Soil aggregate and crop yield changes with different rates of straw incorporation in semiarid areas of northwest China. Geoderma 230-231:41-49. doi:10.1016/j.geoderma.2014.04.007

Zhao, H., B. Sun, L. Jiang, F. Lu, X. Wang, and Z. Ouyang. 2014. How can straw incorporation management impact on soil carbon storage? A meta-analysis. Mitig. Adapt. Strateg. Glob. Change. doi:10.1007/s11027-014-9586-z.

Zhao, Q., S. Zhou, S. Wu, and K. Ren. 2006. Cultivated land resources and strategies for its sustainable utilization and protection in China. (In Chinese with English abstract.) Acta Pedologica Sinica 43:662-672.

Zhao, X., K. Hu, K. Li, P. Wang, Y. Ma, and K. Stahr. 2013. Effect of optimal irrigation, different fertilization, and reduced tillage on soil organic carbon storage and crop yields in the North China Plain. J. Plant Nutr. Soil Sci. 176:89-98. doi:10.1002/jpln.201100353

Zhou, Y., Z.H. He, X.X. Sui, X.C. Xia, X.K. Zhang, and G.S. Zhang. 2007. Genetic improvement of grain yield and associated traits in the Northern China winter wheat region from 1960 to 2000. Crop Sci. 47:245-253. doi:10.2135/cropsci2006.03.0175

Zhu, Z.L., and D.L. Chen. 2002. Nitrogen fertilizer use in ChinaContributions to food production, impacts on the environment and best management strategies. Nutr. Cycling Agroecosyst. 63:117-127. doi:10.1023/A:1021107026067 